\title{
Physicochemical and functional characterization of a biosurfactant produced by Lactococcus lactis 53
}

\author{
Lígia R. Rodrigues ${ }^{\mathrm{a}, *}$, José A. Teixeira ${ }^{\mathrm{a}}$, Henny C. van der Mei ${ }^{\mathrm{b}}$, Rosário Oliveira ${ }^{\mathrm{a}}$ \\ ${ }^{a}$ Centro de Engenharia Biológica, Universidade do Minho, Campus de Gualtar, 4710-057 Braga, Portugal \\ ${ }^{\mathrm{b}}$ Department of Biomedical Engineering, University Medical Center Groningen and University of Groningen, \\ Antonius Deusinglaan 1, 9713 AV Groningen, The Netherlands
}

Received 1 February 2006; received in revised form 28 February 2006; accepted 5 March 2006

\begin{abstract}
Isolation and identification of key components of the crude biosurfactant produced by Lactococcus lactis 53 was studied. Fractionation was achieved by hydrophobic interaction chromatography which allowed the isolation of a fraction rich in glycoproteins. Molecular (by Fourier transform infrared spectroscopy) and elemental compositions (by X-ray photoelectron spectroscopy) were determined. Critical micelle concentration achieved for the isolated fraction was $14 \mathrm{~g} / \mathrm{l}$, allowing for a surface tension value of $36 \mathrm{~mJ} / \mathrm{m}^{2}$. Moreover, the isolated fraction, stable to $\mathrm{pH}$ changes between 5 and 9, was found to be an anti-adhesive and antimicrobial agent against several bacterial and yeast strains isolated from explanted voice prostheses, even at low concentrations. Further purification steps should be carefully analyzed as each purification step will increase the costs and decreases the amounts of biosurfactants recovered.
\end{abstract}

(C) 2006 Elsevier B.V. All rights reserved.

Keywords: Biosurfactant; Lactococcus lactis 53; Isolation; Physicochemical characterization

\section{Introduction}

Biosurfactants are microbial compounds with a pronounced surface activity that exhibit a wide variety of chemical structures, such as glycolipids, lipopeptides, polysaccharide-protein complexes, protein-like substances, lipopolysaccharides, phospholipids, fatty acids and neutral lipids [1-5]. Therefore, it is reasonable to expect diverse properties and physiological functions for different groups of biosurfactants. A host of interesting features of biosurfactants have lead to a broad range of potential applications in the biomedical field. They are not only useful as antibacterial, antifungal and antiviral agents, but also have potential for use as major immunomodulatory molecules, antiadhesive agents and even in vaccines and gene therapy [5-9]. Involvement of biosurfactants in microbial adhesion and desorption has been widely described. For example, inhibition of uropathogen biofilm formation on silicone rubber by protein-like

\footnotetext{
* Corresponding author at: Centro de Engenharia Biológica, IBQF, Universidade do Minho, Largo do Paço, 4719 Braga Codex, Portugal. Tel.: +351 253 604400; fax: +351253678986.

E-mail address: 1rmr@deb.uminho.pt (L.R. Rodrigues).
}

biosurfactants obtained from Lactobacillus fermentum RC-14 was reported [10-12]. Also, exposure to suspensions of active probiotics and the consumption of buttermilk containing Lactococcus lactis 53 were reported to influence the biofilm formation on silicone rubber voice prostheses [13,14], possibly due to the release of biosurfactants. Although there are a few well known biosurfactants, as for example surfactin and iturin produced by Bacillus subtilis [15,16], rhamnolipids produced by Pseudomonas aeruginosa [6] or mannosylerythritol lipids produced by Candida antartica [17], information on the chemical structure of biosurfactants produced by probiotic microorganisms is scarce.

The crude biosurfactant produced by L. lactis 53 fractionated and characterized in this study was previously found to be an antimicrobial and anti-adhesive agent with great potential for use in biomedical applications, namely to coat silicone rubber voice prostheses in order to inhibit their microbial colonization and prolong their lifetime [7,18]. The aim of this study was to isolate and identify key components of the crude biosurfactant mixture produced by L. lactis 53 , including its molecular composition (by Fourier transform infrared spectroscopy) and elemental composition (by X-ray photoelectron spectroscopy). Moreover, its partial functional characterization was established 
by the determination of the antimicrobial and anti-adhesive activity. Finally, its cleaning ability, critical micelle concentration and stability at several $\mathrm{pH}$ was evaluated.

\section{Materials and methods}

\subsection{Microbial strains and culture conditions}

The biosurfactant-producing strain used was L. lactis 53 obtained from Nutricia (The Netherlands). L. lactis 53 was stored at $-20^{\circ} \mathrm{C}$ in MRS broth (medium introduced by De Man, Rogosa and Sharpe for cultivation of Lactobacillus species, OXOID, Basingstoke, England) containing 15\% (v/v) glycerol solution until ready to use. From frozen stock, bacteria were streaked on MRS agar plates and incubated at $37^{\circ} \mathrm{C}$ for further culturing. To prepare subcultures, the medium was inoculated with a colony from the plate and incubated overnight under the same conditions.

Four bacterial strains, Staphylococcus epidermidis GB 9/6, Streptococcus salivarius GB 24/9, Staphylococcus aureus GB 2/1 and Rothia dentocariosa GBJ 52/2B and two yeast strains, Candida albicans GBJ 13/4A and Candida tropicalis GB 9/9 isolated from explanted voice prostheses were used in the antiadhesion and antimicrobial assays. All strains were first grown overnight at $37^{\circ} \mathrm{C}$ on agar plates from frozen stocks, the agar plates were kept at $4{ }^{\circ} \mathrm{C}$, never longer than 2 weeks. Several colonies were used to inoculate $10 \mathrm{ml}$ of brain heart infusion broth (BHI, OXOID, Basingstoke, England) for all the microbial strains in use. This preculture was incubated at $37^{\circ} \mathrm{C}$ for $24 \mathrm{~h}$ and used to inoculate a second culture of $200 \mathrm{ml}$ that was grown statically for $18 \mathrm{~h}$. The microorganisms from the second culture were harvested by centrifugation for $5 \mathrm{~min}$ at $10,000 \times g$ and washed twice with demineralized water. Subsequently, bacterial cells were suspended in $200 \mathrm{ml}$ phosphate buffered saline (PBS: $10 \mathrm{mM} \mathrm{KH} \mathrm{PO}_{4} / \mathrm{K}_{2} \mathrm{HPO}_{4}$ and $150 \mathrm{mM} \mathrm{NaCl}$ with $\mathrm{pH}$ adjusted to 7.0$)$, after sonication on ice (10 s), to a concentration of $3 \times 10^{8} \mathrm{ml}^{-1}$. The sonication procedure did not promote cell lysis. Yeasts were suspended in PBS to a concentration of $3 \times 10^{6} \mathrm{ml}^{-1}$. A Bürker-Türk counting chamber was used to count the cells.

\subsection{Biosurfactant production and isolation}

The production of crude biosurfactant obtained from L. lactis 53 was released as described elsewhere [18,19]. Briefly, $600 \mathrm{ml}$ of MRS broth was incubated with $15 \mathrm{ml}$ of an overnight L. lactis 53 subculture and incubated for $18 \mathrm{~h}$. Cells were harvested by centrifugation $\left(10,000 \times g, 5 \mathrm{~min}, 10^{\circ} \mathrm{C}\right)$, washed twice in demineralized water, and resuspended in $100 \mathrm{ml}$ PBS. The bacteria were left at room temperature for $2 \mathrm{~h}$ with gentle stirring for biosurfactant release. Subsequently, the bacteria were removed by centrifugation and the remaining supernatant liquid was filtered through a $0.22 \mu \mathrm{m}$ pore-size filter (Millipore). The supernatant was dialyzed against demineralized water at $4{ }^{\circ} \mathrm{C}$ in a Spectrapor membrane tube (molecular weight cut off 6000-8000, Spectrum Medical Industries Inc., CA) and freeze-dried, and the crude biosurfactant was used for further studies.

\subsection{Hydrophobic interaction chromatography}

Hydrophobic interaction chromatography (HIC) was used as a technique for the purification and separation of biomolecules based on differences in their surface hydrophobicity. Fractionation was performed on an Octyl Sepharose 4 FF Prep hydrophobic interaction column ( $20 \mathrm{ml}$, Pharmacia Biotech). Freeze-dried crude biosurfactant (100 g/l) was prepared in a PBS buffer solution ( $\mathrm{pH} 7.0)$ containing $1.0 \mathrm{M}\left(\mathrm{NH}_{4}\right)_{2} \mathrm{SO}_{4}$ and loaded $(500 \mu \mathrm{l})$ onto the column equilibrated in the same buffer. Elution was carried out with a $60 \mathrm{ml}$ linear gradient from 1 to $0 \mathrm{M}\left(\mathrm{NH}_{4}\right)_{2} \mathrm{SO}_{4}$ in PBS buffer (flow rate, $60 \mathrm{ml} / \mathrm{h}$; fractions, $2.5 \mathrm{ml}$ ). Absorbance at $280 \mathrm{~nm}$ was recorded, using a L-7455 Diode-Array detector (Merck), and analyzed with D-7000 HPLC System Manager (Version 3.1) Software. The protein content of the eluted fractions was determined according to the Bradford method with Coomassie brilliant blue using bovine serum albumin as standard. The total sugar content of the eluted fractions was evaluated by the phenol-sulphuric method described by Dubois et al. [20] using glucose as standard. All the fractions eluted were tested for surface activity by measuring the surface tension of the samples with the Ring method, as described elsewhere [21]. Three surface active fractions were obtained from this fractionation procedure: fraction $\mathrm{A}, \mathrm{B}$ and $\mathrm{C}$. The isolated fractions were dialyzed against demineralized water at $4{ }^{\circ} \mathrm{C}$ in a Spectrapor membrane tube (molecular weight cut off 6000-8000, Spectrum Medical Industries Inc., CA) and freeze-dried.

\subsection{Oil spreading test}

The oil spreading test measures the diameter of clear zones caused when a drop of a biosurfactant-containing solution is placed on an oil-water surface. The binomial diameter and biosurfactant concentration allows the determination of the cleaning efficiency of a given biosurfactant. For the oil spreading test, $50 \mathrm{ml}$ of distilled water was added to a large Petri dish $(25 \mathrm{~cm}$ diameter) followed by addition of $20 \mu \mathrm{l}$ of crude oil to the surface of water, $10 \mu \mathrm{l}$ of crude biosurfactant and isolated fractions (A, B and C) dissolved in PBS (at concentrations ranging from 2.5 to $40 \mathrm{~g} / \mathrm{l}$ ) were then added to the surface of oil. Also, a control plate was evaluated with PBS. The diameters of clear zones of triplicate assays from the same sample were determined.

\subsection{Critical micelle concentration ( $\mathrm{cmc}$ ) and biosurfactant stability}

Critical micelle concentration (cmc) is a measure of the concentration of a solution component which represents a critical value above which increasing concentration of that component forces the formation of micelles. It is important for several applications of biosurfactants to establish their $\mathrm{cmc}$, as above this concentration no further effect is expected in the surface activity. The cmc was determined by plotting the surface tension as a function of the logarithm of biosurfactant concentration and is found as the point at which the baseline of minimal surface tension intersects the slope where surface tension shows a linear decline. Concentrations ranging from 2.5 to $40 \mathrm{~g} / \mathrm{l}$ of the 
crude biosurfactants and isolated fractions (A, B and C) were prepared in PBS. The surface tension of each sample was determined by the Ring method [21] using a KRUSS Tensiometer equipped with a $1.9 \mathrm{~cm}$ De Noüy platinum ring at room temperature $\left(25 \pm 1^{\circ} \mathrm{C}\right)$. Measurements were done in triplicate.

The applicability of the biosurfactants can be conditioned by its stability to $\mathrm{pH}$ changes, thus crude biosurfactant and isolated fractions (A, B and C) were prepared with a $40 \mathrm{~g} / \mathrm{l}$ concentration at several $\mathrm{pH}(\mathrm{pH} 4-10, \mathrm{PBS})$. To determine the $\mathrm{pH}$ stability of each crude biosurfactant and isolated fraction the surface tension was measured by the Ring method [21].

\subsection{Fourier transform infrared spectroscopy}

Fourier transform infrared spectroscopy (FTIR) is most useful for identifying types of chemical bonds (functional groups), therefore can be used to elucidate some components of an unknown mixture. The molecular characterization was performed using crude biosurfactant mixture and fraction A (as this was the most surface active fraction). One milligram of freeze-dried crude biosurfactant and fraction A were ground with $100 \mathrm{mg}$ of $\mathrm{KBr}$ and pressed with $7500 \mathrm{~kg}$ for $30 \mathrm{~s}$ to obtain translucent pellets. Infrared absorption spectra were recorded on a FTIR/Diffus Bomem MB spectrometer with a spectral resolution and wavenumber accuracy of 4 and $0.01 \mathrm{~cm}^{-1}$, respectively. All measurements consisted of 500 scans, and a $\mathrm{KBr}$ pellet was used as background reference. Quantification of a spectral region of interest was obtained by normalizing the area under the absorption bands with respect to the area of the $\mathrm{CH}$ absorption band around $2920 \mathrm{~cm}^{-1}$.

\subsection{X-ray photoelectron spectroscopy}

X-ray photoelectron spectroscopy (XPS) is a surface analysis technique used for obtaining chemical information about the surfaces of solid materials. The elemental composition was determined for the crude biosurfactant mixture and fraction $\mathrm{A}$. Freeze-dried crude biosurfactant and fraction A were dissolved in demineralized water $(30 \mathrm{~g} / \mathrm{l})$ and $10 \mu \mathrm{l}$ droplets were placed on gold-coated glass slides $(1 \mathrm{~cm} \times 1 \mathrm{~cm})$. After air drying, glass slides were inserted into the chamber of the spectrometer (Surface Science Instruments, S-probe). The residual pressure in the spectrometer was approximately $10^{-9} \mathrm{~Pa}$. A magnesium anode was used for X-ray production $(10 \mathrm{kV}, 22 \mathrm{~mA})$ at a spot size of $250 \mu \mathrm{m} \times 1000 \mu \mathrm{m}$. After a scan of the overall spectrum in the binding energy range $1-1200 \mathrm{eV}$ at low resolution $(150 \mathrm{eV}$ pass energy), peaks over a $20 \mathrm{eV}$ binding energy range were recorded at high resolution ( $50 \mathrm{eV}$ pass energy) in the following order: C 1s, O 1s, N 1s, P 2p, and C 1s again in order to be able to account for contamination or deterioration of the samples caused by X-ray irradiation. The areas under the peaks, after Shirley background subtraction and correction with instrument sensitivity factors, were used to calculate the elemental surface concentration ratios $\mathrm{N} / \mathrm{C}, \mathrm{O} / \mathrm{C}$ and $\mathrm{P} / \mathrm{C}$.

The $\mathrm{C}$ 1s peak was decomposed by a least-squares fitting program into four Gaussian components set at $284.5 \mathrm{eV}$ (C1), $285.9 \mathrm{eV}(\mathrm{C} 2), 287.3 \mathrm{eV}(\mathrm{C} 3)$ and $289.2 \mathrm{eV}$ (C4) by imposing a constant full width at half maximum of $1.35 \mathrm{eV}$; these four components were thought to be representative of the carbon involved in $\mathrm{C}-\mathrm{C}$ and $\mathrm{C}-\mathrm{H}$ bonds, $\mathrm{C}-\mathrm{O}$ and $\mathrm{C}-\mathrm{N}$ bonds (including ether, alcohol, amine or amide [22]) $(\mathrm{C}=\mathrm{O})-\mathrm{N}$ and $(\mathrm{C}=\mathrm{O})-\mathrm{O}$ bonds (including amide, carbonyl, carboxylate, acetal or hemiacetal or amide [23]), and $(\mathrm{C}=\mathrm{O})-\mathrm{OH}$, respectively. The oxygen peak was split into two components at $530.3 \mathrm{eV}(\mathrm{O} 1)$ and $531.8 \mathrm{eV}(\mathrm{O} 2)$ by imposing a constant full width at half maximum of $1.70 \mathrm{eV}$ and thought to be representative of oxygen involved in $\mathrm{O}=\mathrm{C}$ and $\mathrm{C}-\mathrm{O}$ bonds, respectively.

\subsection{Anti-adhesion assay in 96 wells plate}

The anti-adhesive activity of the crude biosurfactant and isolated fractions (A, B and C) against the microbial strains isolated from explanted voice prostheses described above was quantified according to a previously reported adhesion assay [12,24]. Briefly, the wells of a sterile 96-well flat-bottomed plastic tissue culture plate with a lid were filled with $200 \mu$ l of the crude biosurfactant and isolated fractions (A, B and C) to be tested for anti-adhesive activity. Several concentrations were tested ranging from 2.5 to $40 \mathrm{~g} / \mathrm{l}$. The plate was incubated for $18 \mathrm{~h}$ at $4{ }^{\circ} \mathrm{C}$ and subsequently washed twice with PBS. Control wells contained buffer (PBS) only. A $200 \mu$ l aliquot of a washed bacterial or yeast suspension was added and incubated in the wells for $4 \mathrm{~h}$ at $4{ }^{\circ} \mathrm{C}$. Unattached organisms were removed by washing the wells three times with PBS. The adherent microorganisms were fixed with $200 \mu \mathrm{l}$ of $99 \%$ methanol per well, and after $15 \mathrm{~min}$ the plates were emptied and left to dry. Then the plates were stained for 5 min with $200 \mu$ l of $2 \%$ crystal violet used for Gram staining per well. Excess stain was rinsed of by placing the plate under running tap water. Subsequently the plates were air dried, the dye bound to the adherent microorganisms was resolubilized with $200 \mu \mathrm{l}$ of $33 \%$ (v/v) glacial acetic acid per well and the optical density readings of each well were taken at $595 \mathrm{~nm}$. The microtiter-plate anti-adhesion assay allows the estimation of the crude biosurfactant and isolated fractions concentrations that are effective in inhibiting adhesion of the microorganisms studied.

\subsection{Antimicrobial assay}

The microorganisms used for the growth inhibition test were the same as used in the anti-adhesion assay in 96 wells plate described above. The growth inhibition test was performed as described by Elving et al. [24]. Briefly, yeasts and bacteria cultured overnight under appropriate conditions were harvested by centrifugation and diluted in reduced transport fluid (RTF: $0.9 \mathrm{~g} / 1$ $\mathrm{NaCl}, 0.9 \mathrm{~g} / \mathrm{l}\left(\mathrm{NH}_{4}\right)_{2} \mathrm{SO}_{4}, 0.45 \mathrm{~g} / 1 \mathrm{KH}_{2} \mathrm{PO}_{4}, 0.19 \mathrm{~g} / 1 \mathrm{MgSO}_{4}$, $0.45 \mathrm{~g} / 1 \mathrm{~K}_{2} \mathrm{HPO}_{4}, 0.37 \mathrm{~g} / 1 \mathrm{Na}_{2}$ EDTA, $0.2 \mathrm{~g} / 1 \mathrm{~L}$-cysteine $\mathrm{HCl}, \mathrm{pH}$ $6.8)$ to a concentration allowing confluent growth when plated with a cotton swab on the agar. Yeasts were plated on MRS agar, while bacteria were plated on brain heart infusion agar (OXOID, Basingstoke, England). Agar plates were dried for $20 \mathrm{~min}$ at room temperature and $5 \mu \mathrm{l}$ isolated fractions (A, B and $\mathrm{C}$ ) of several concentrations (ranging from 2.5 to $40 \mathrm{~g} / \mathrm{l}$ ), were spotted onto the surface of the agar plate. After overnight incubation, the 
agar plates were screened for growth inhibition zones around the isolated fraction spots.

\section{Results}

\subsection{Partial purification of the biosurfactants}

Fig. 1 shows the fractionation profile of the crude biosurfactant obtained from $L$. lactis 53 regarding total protein and total sugar content, absorbance at $280 \mathrm{~nm}$ and surface tension. The crude biosurfactant had a surface tension of $36 \mathrm{~mJ} / \mathrm{m}^{2}$, an absorbance at $280 \mathrm{~nm}$ of 3.096 , a total sugar content of $0.235 \mathrm{~g} / \mathrm{l}$ and a total protein content of $0.587 \mathrm{~g} / \mathrm{l}$. From hydrophobic interaction chromatography experiment three different fractions are isolated: fraction A (from 20 to $27.5 \mathrm{~min}$ ), fraction B (from 35 to $40 \mathrm{~min}$ ) and fraction $\mathrm{C}$ (from 42.5 to $47.5 \mathrm{~min}$ ) with surface tensions 36,47 and $56 \mathrm{~mJ} / \mathrm{m}^{2}$, respectively. Fraction A exhibited the higher values of absorbance at $280 \mathrm{~nm}(0.163)$, total sugar content $(0.025 \mathrm{~g} / \mathrm{l})$ and total protein content $(0.046 \mathrm{~g} / \mathrm{l})$ as compared to fractions $\mathrm{B}$ and $\mathrm{C}$. The isolated fractions $\mathrm{A}, \mathrm{B}$ and $\mathrm{C}$ were used for further studies.

\subsection{Oil spreading capacity}

The clearing zones are an indirect measure of the surface activity of the tested samples against hydrocarbons, thus the higher diameters represent the most surface active samples. Table 1 presents the zones of clearing on the oil surface of the crude biosurfactant and isolated fractions (A, B and C) at different concentrations. For each tested sample a linear relationship between concentration and diameter of the clearing zone could be observed at a concentration above $5 \mathrm{~g} / \mathrm{l}$. Comparing crude biosurfactant with isolated fractions it was observed that fraction A had a higher surface activity than crude biosurfactant. Fractions $\mathrm{B}$ and $\mathrm{C}$ showed lower surface activities as lower diameters were found. At concentrations below $5 \mathrm{~g} / \mathrm{l}$ small clear zones were observed for all tested samples.

\subsection{Critical micelle concentration (cmc) and biosurfactant stability}

The critical micelle concentration $(\mathrm{cmc}$ ) for the crude biosurfactant and isolated fractions (A, B and C) is illustrated in Fig. 2.
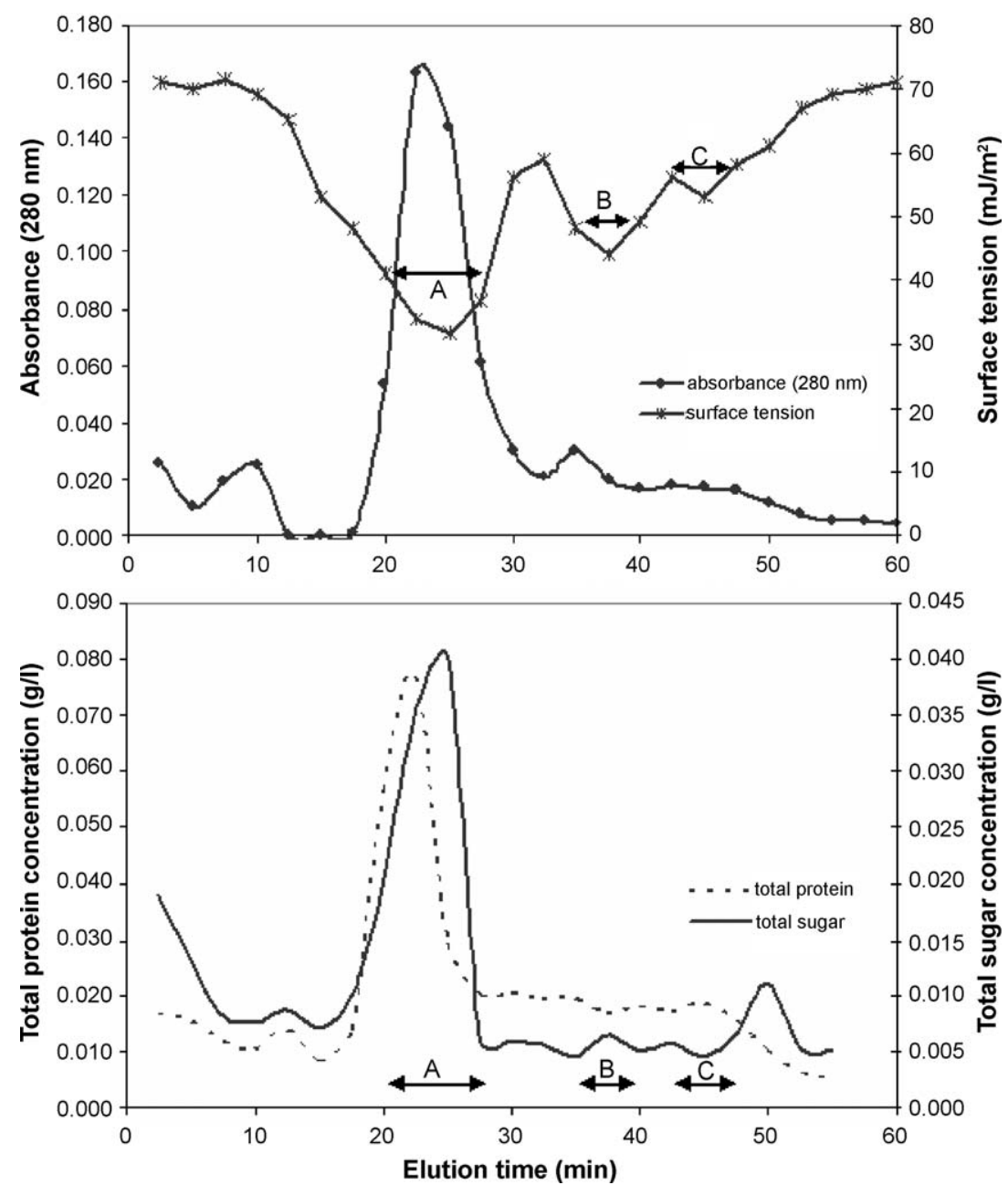

Fig. 1. Elution profile of the crude biosurfactant obtained from Lactococcus lactis 53 on Octyl Sepharose 4 FF Prep column. Fractions were eluted with a linear gradient from 1 to $0 \mathrm{M}\left(\mathrm{NH}_{4}\right)_{2} \mathrm{SO}_{4}$ in PBS buffer. Fractions were collected and monitored by absorbance at $280 \mathrm{~nm}$, total sugars (phenol-sulphuric method), total protein (Bradford method) and surface tension (Ring method). Results represent the average of three independent experiments. 
Table 1

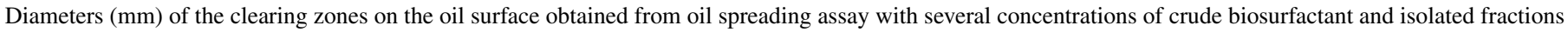

\begin{tabular}{|c|c|c|c|c|c|c|}
\hline \multirow[t]{3}{*}{ Sample } & \multicolumn{6}{|c|}{ Diameter of the clearing zone (mm) } \\
\hline & \multicolumn{6}{|c|}{ Crude biosurfactant and isolated fractions concentrations $(\mathrm{g} / \mathrm{l})$} \\
\hline & PBS control & 2.5 & 5 & 10 & 20 & 40 \\
\hline Crude biosurfactant & 0.0 & $1.2 \pm 0.09$ & $4.5 \pm 0.03$ & $7.2 \pm 0.12$ & $8.8 \pm 0.07$ & $11.5 \pm 0.02$ \\
\hline Fraction A & 0.0 & $2.1 \pm 0.14$ & $6.9 \pm 0.02$ & $8.5 \pm 0.05$ & $9.6 \pm 0.05$ & $12.4 \pm 0.07$ \\
\hline Fraction B & 0.0 & $0.1 \pm 0.02$ & $3.6 \pm 0.08$ & $4.9 \pm 0.01$ & $7.3 \pm 0.03$ & $8.8 \pm 0.07$ \\
\hline Fraction $\mathrm{C}$ & 0.0 & $0.1 \pm 0.01$ & $2.9 \pm 0.09$ & $4.2 \pm 0.09$ & $6.1 \pm 0.05$ & $7.8 \pm 0.15$ \\
\hline
\end{tabular}

PBS was used as control with a diameter of $0.0 \mathrm{~mm}$ as no clearing zone occurs. Standard deviations $( \pm)$ were determined over three separate measurements.

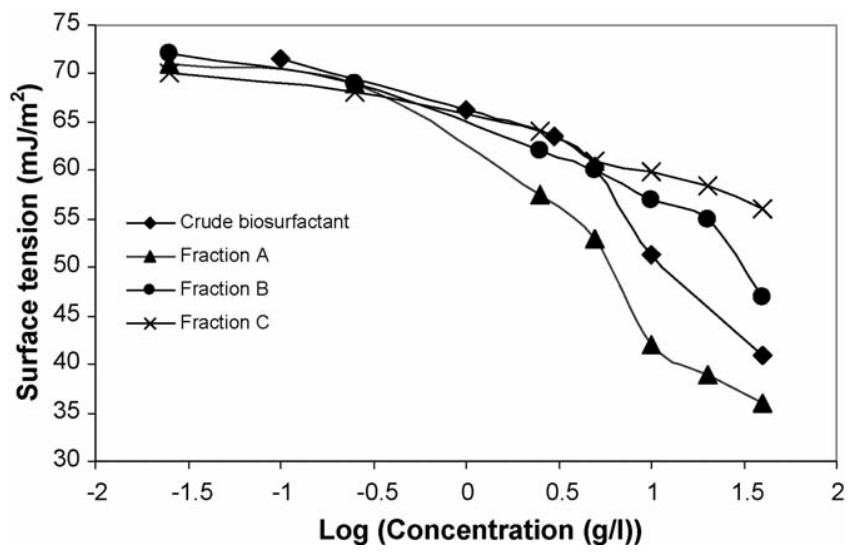

Fig. 2. Surface tension vs. concentrations of the crude biosurfactant and isolated fractions obtained from L. lactis 53. Results represent the average of three independent experiments.

Fraction A was found to be the most surface active sample, with $\mathrm{cmc}$ of $14 \mathrm{~g} / \mathrm{l}$, thus similar to the crude biosurfactant. Fraction $\mathrm{B}$ showed small decreases in the surface tensions despite of the increasing concentrations ( $\mathrm{cmc}$ of $35 \mathrm{~g} / \mathrm{l}$ ), and for fraction $\mathrm{C}$ almost no decrease was observed ( $\mathrm{cmc}$ of $52 \mathrm{~g} / \mathrm{l}$ ).

The surface tension reducing activity of the crude biosurfactant and fraction A was relatively stable to $\mathrm{pH}$ changes (Table 2). The surface tensions remained stable over a $\mathrm{pH}$ range from 5 to 9, although there was a slight increase at pHs 4 and 10. All the tested samples became turbid below $\mathrm{pH} 4$ due to precipitation. For fractions $\mathrm{B}$ and $\mathrm{C}$ the surface tensions were only stable between pH 6 and 8. The molecular and elemental characteri-

Table 2

Surface tension measurements of crude biosurfactant and isolated fractions with a concentration of $40 \mathrm{~g} / \mathrm{l}$ at several $\mathrm{pH}$ values, as determined by the Ring method

\begin{tabular}{rllll}
\hline $\mathrm{pH}$ & \multicolumn{3}{l}{ Surface tension $\left(\mathrm{mJ} / \mathrm{m}^{2}\right)$} & \\
\cline { 2 - 5 } & Crude biosurfactant & Fraction A & Fraction B & Fraction C \\
\hline 4 & 45.6 & 38.4 & 66.7 & 72.1 \\
5 & 41.1 & 35.3 & 58.9 & 71.8 \\
6 & 39.8 & 36.1 & 47.8 & 64.7 \\
7 & 41.0 & 36.1 & 47.2 & 56.4 \\
8 & 39.9 & 36.2 & 47.4 & 57.4 \\
9 & 42.2 & 37.4 & 60.7 & 62.2 \\
10 & 47.2 & 43.2 & 71.2 & 65.4 \\
\hline
\end{tabular}

Experiments were performed in triplicate and correspond within $18 \%$. zation was performed for the crude biosurfactant and fraction $\mathrm{A}$ as this fraction was found to be the most surface active.

\subsection{Fourier transform infrared spectroscopy}

The molecular composition of the crude biosurfactant and fraction A was evaluated by Fourier transform infrared spectroscopy. Fig. 3 presents the spectra of the freeze-dried samples. Both spectra showed essentially the same absorption bands, and only the relative areas under the various absorption bands differed. The most important bands were located at $2920 \mathrm{~cm}^{-1}$ ( $\mathrm{CH}$ band: $\mathrm{CH}_{2}-\mathrm{CH}_{3}$ stretching), $1655 \mathrm{~cm}^{-1}$ (AmI band: $\mathrm{C}=\mathrm{O}$ stretching in proteins), $1551 \mathrm{~cm}^{-1}$ (AmII band: $\mathrm{N}-\mathrm{H}$ bending in proteins), $1254 \mathrm{~cm}^{-1}$ (PI band: phosphates) and $1065 \mathrm{~cm}^{-1}$ (PII band: polysaccharides). Absorption band ratios of AmI, AmII, PI and PII with respect to the $\mathrm{CH}$ band of 1.3, 1.0, 0.9 and 2.1 , respectively, were obtained for the crude biosurfactant. For fraction A lower absorption band ratios were achieved (1.0, 0.9, 0.5 and 1.8 for $\mathrm{AmI} / \mathrm{CH}, \mathrm{AmII} / \mathrm{CH}, \mathrm{PI} / \mathrm{CH}$ and $\mathrm{PII} / \mathrm{CH}$, respectively). The crude biosurfactant spectra (Fig. 3) showed that this biosurfactant consist of a mixture of several compounds as it was detected a pronounced absorption band at $2500 \mathrm{~cm}^{-1}$ (indicative of the presence of protonated amines), the AmI and AmII bands (indicative of protein), and the PI (phosphates) and PII (polysaccharides) bands. Although for fraction A and

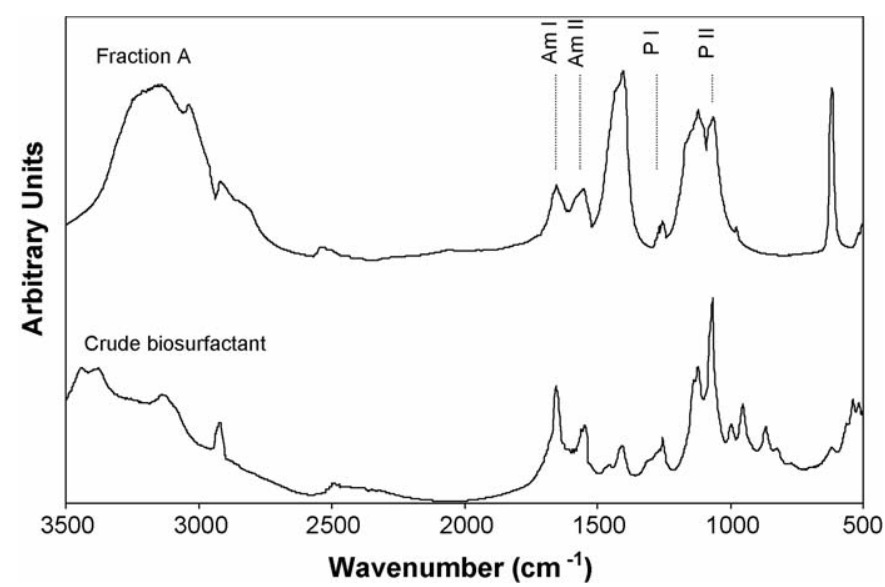

Fig. 3. Fourier transform infrared absorption spectra of crude biosurfactant and isolated fraction A obtained from L. lactis 53. The absorption bands used for quantification are indicated. 
Table 3

Chemical composition data by XPS of crude biosurfactant, isolated fraction A and reference compounds (for comparison)

\begin{tabular}{|c|c|c|c|c|c|c|c|c|c|}
\hline \multirow[t]{2}{*}{ Compound } & \multicolumn{3}{|c|}{ Elemental composition } & \multicolumn{6}{|c|}{ Fractions of $\mathrm{C}$ and $\mathrm{O}$ atoms } \\
\hline & $\mathrm{N} / \mathrm{C}$ & $\mathrm{O} / \mathrm{C}$ & $\mathrm{P} / \mathrm{C}$ & $\mathrm{C} 1$ & $\mathrm{C} 2$ & $\mathrm{C} 3$ & $\mathrm{C} 4$ & $\mathrm{O} 1$ & $\mathrm{O} 2$ \\
\hline Crude biosurfactant & 0.16 & 0.61 & 0.06 & 0.29 & 0.44 & 0.18 & 0.10 & 0.41 & 0.59 \\
\hline Fraction A & 0.20 & 0.65 & 0.04 & 0.70 & 0.22 & 0.05 & 0.03 & 0.62 & 0.38 \\
\hline \multicolumn{10}{|l|}{ Reference compounds } \\
\hline Glycosidic residue $^{a}$ & 0.00 & 0.83 & 0.00 & 0.00 & 0.83 & $0.17^{\mathrm{b}}$ & & 0.00 & 1.00 \\
\hline Phospholipid $^{\mathrm{c}}$ & 0.01 & 0.21 & 0.03 & 0.82 & 0.13 & 0.05 & 0.01 & 0.37 & 0.63 \\
\hline Cholesterol & 0.00 & 0.03 & 0.00 & 0.87 & 0.12 & 0.00 & 0.00 & 0.00 & 1.00 \\
\hline LTA $^{\mathrm{d}}$ & 0.03 & 0.63 & 0.07 & 0.41 & 0.44 & 0.44 & 0.05 & 0.24 & 0.76 \\
\hline Protein ${ }^{\mathrm{e}}$ & 0.27 & 0.32 & 0.00 & 0.41 & 0.32 & $0.28^{b}$ & & 0.86 & 0.14 \\
\hline Salivary glycoprotein ${ }^{\mathrm{f}}$ & 0.18 & & & 0.52 & 0.32 & $0.16^{\mathrm{b}}$ & & & \\
\hline
\end{tabular}

${ }^{a}$ Glycosidic residue $\mathrm{C}_{6} \mathrm{H}_{10} \mathrm{O}_{5}$ [29].

b $\mathrm{C} 3$ and $\mathrm{C} 4$ together.

c L- $\alpha$-Phosphatidyl-DL-glycerol dimyristoyl [29].

d Lipoteichoic acid from S. mutans (Sigma).

e Average protein, calculated for a collection of bacterial, fungal and mammalian proteins [29].

f Data from Velraeds et al. [3].

crude biosurfactant spectras the same absorption bands were found, fraction A exhibited a similar protein content but less polysaccharide and phosphate contents as compared to the crude biosurfactant.

\subsection{X-ray photoelectron spectroscopy}

X-ray photoelectron spectroscopy of the freeze-dried crude biosurfactant and fraction A yielded the elemental surface concentration ratio N/C, O/C, P/C and the components of the $\mathrm{C}_{1 \mathrm{~s}}$ and $\mathrm{O}_{1 \mathrm{~s}}$ peaks (Table 3). From the N/C ratio and $\mathrm{C} 3+\mathrm{C} 4$ peak fractions, it can be concluded that crude biosurfactant and fraction $\mathrm{A}$ are rich in protein. The fractionation of the crude biosurfactant resulted in a fraction (A) where the high $\mathrm{N} / \mathrm{C}$ and $\mathrm{O} / \mathrm{C}$ ratios together with the higher percentage of carbon involved in $\mathrm{C} 1$ bonds and oxygen $\mathrm{O} 1$ bonds indicates that the material probably contains glycoproteins.

\subsection{Anti-adhesive activity}

The anti-adhesive activity of the crude biosurfactant and isolated fractions (A, B and C) was evaluated at several concentrations and compared against a variety of bacterial and yeast strains isolated from explanted voice prostheses (Table 4). The

Table 4

Microbial inhibition percentages obtained from the microtiter-plate anti-adhesion assay with several crude biosurfactant and isolated fractions (A, B and C) at different concentrations $(\mathrm{g} / \mathrm{l})$

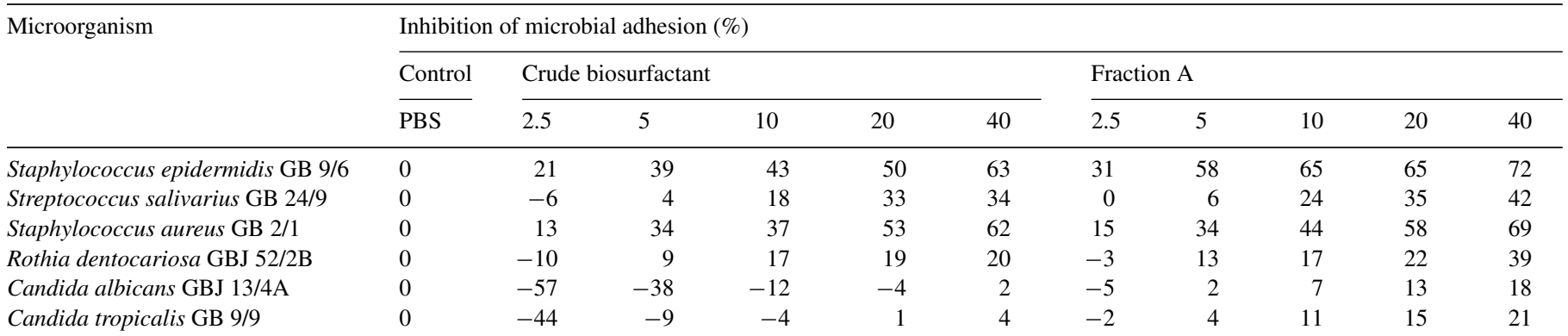

Microorganism

Inhibition of microbial adhesion (\%)

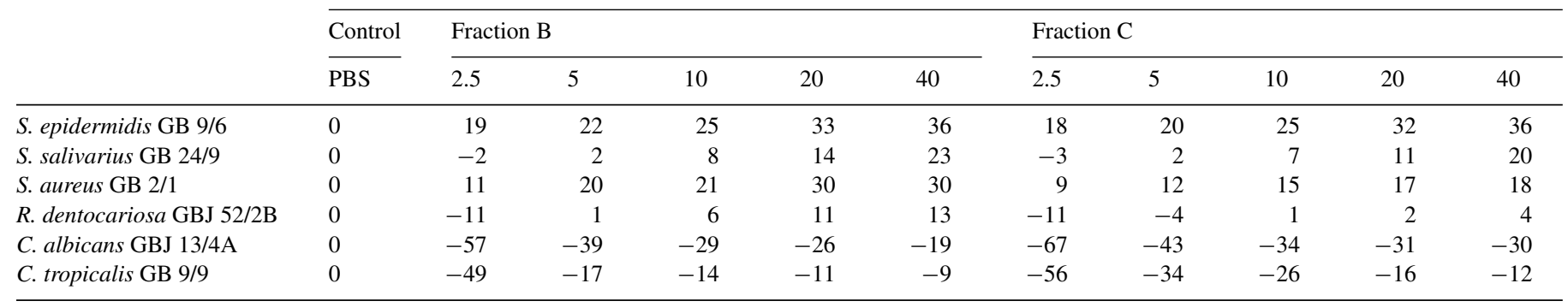

PBS was used as control and set at $0 \%$ as no microbial inhibition occurs. Experiments were performed in triplicate and correspond within $20 \%$. 
crude biosurfactant and fraction $\mathrm{A}$ had an anti-adhesive effect against all microorganisms tested but the anti-adhesive effect is depending on the concentration and microorganism tested. Both the crude biosurfactant and fraction A showed the highest antiadhesive activity against $S$. epidermidis GB $9 / 6$ and $S$. aureus GB 2/1 with inhibition percentages till $70 \%$ and worked even at a concentration of $2.5 \mathrm{~g} / \mathrm{l}$. Moreover, the yeast strains were found to be inhibited only by fraction A. Fractions B and C showed far less inhibition percentages when compared to the crude biosurfactant.

\subsection{Antimicrobial activity}

The antimicrobial activities of the isolated fractions (A, $\mathrm{B}$ and $\mathrm{C}$ ) were evaluated at several concentrations and compared to a variety of bacterial and yeast strains isolated from explanted voice prostheses (Table 5). Fraction A was found to be an antimicrobial agent but, depending on the microorganism, there are different effective concentrations. It was found that fraction $\mathrm{A}$ exhibited a high antimicrobial activity against C. tropicalis GB 9/9 even at low concentrations. At the highest concentration tested $(40 \mathrm{~g} / \mathrm{l})$ fraction A was active against all bacterial and yeast strains involved in this study, except for $R$. dentocariosa GBJ 52/2B which formed some colonies within the fraction spots. Moreover, it was observed that fractions $\mathrm{B}$ and $\mathrm{C}$ showed no antimicrobial activity against $R$. dentocariosa GBJ 52/2B and low activity against $S$. aureus GB 2/1 and $C$. albicans GBJ 13/4A even at the higher concentration tested.

Table 5

Antimicrobial activity of fractions isolated from crude biosurfactant with different concentrations against several bacterial and yeast strains isolated from explanted voice prostheses

\begin{tabular}{|c|c|c|c|c|c|}
\hline Microorganism & $2.5 \mathrm{~g} / 1$ & $5 \mathrm{~g} / 1$ & $10 \mathrm{~g} / 1$ & $20 \mathrm{~g} / 1$ & $40 \mathrm{~g} / 1$ \\
\hline \multicolumn{6}{|l|}{ Fraction A } \\
\hline S. epidermidis GB 9/6 & \pm & + & + & + & + \\
\hline S. salivarius GB $24 / 9$ & - & - & \pm & \pm & + \\
\hline S. aureus GB $2 / 1$ & + & + & + & + & + \\
\hline R. dentocariosa GBJ 52/2B & - & - & - & \pm & \pm \\
\hline C. albicans GBJ 13/4A & - & - & \pm & \pm & + \\
\hline C. tropicalis GB 9/9 & + & + & + & + & + \\
\hline \multicolumn{6}{|l|}{ Fraction B } \\
\hline S. epidermidis GB $9 / 6$ & \pm & \pm & \pm & \pm & + \\
\hline S. salivarius GB $24 / 9$ & - & - & \pm & + & + \\
\hline S. aureus $\mathrm{GB} 2 / 1$ & - & - & - & - & \pm \\
\hline R. dentocariosa GBJ 52/2B & - & - & - & - & - \\
\hline C. albicans GBJ 13/4A & - & - & - & - & \pm \\
\hline C. tropicalis GB 9/9 & - & - & - & - & + \\
\hline \multicolumn{6}{|l|}{ Fraction $\mathrm{C}$} \\
\hline S. epidermidis GB 9/6 & \pm & + & + & + & + \\
\hline S. salivarius GB $24 / 9$ & \pm & + & + & + & + \\
\hline S. aureus GB 2/1 & - & - & - & \pm & \pm \\
\hline R. dentocariosa GBJ 52/2B & - & - & - & - & - \\
\hline C. albicans GBJ 13/4A & - & - & - & \pm & \pm \\
\hline C. tropicalis GB $9 / 9$ & - & - & \pm & + & + \\
\hline
\end{tabular}

The experiments were scored as positive (+) when growth inhibition was observed (no colonies formed); a $( \pm$ ) sign indicated some colonies formed within the zones; no growth inhibition was marked as negative (-).

\section{Discussion}

Crude biosurfactant obtained from L. lactis 53 was physicochemically and biochemically characterized as a multicomponent biosurfactant, consisting of protein and polysaccharides which possibly contained bound phosphate groups. Distinct fractions with increasing hydrophobicities were isolated as surface active compounds from the crude biosurfactant by hydrophobic interaction chromatography $[25,26]$. The most surface active fraction isolated was fraction A eluted with a high content of salt $(0.6-0.7 \mathrm{M})$ meaning that this compound exhibited a high hydrophilic character. These results are in accordance with previously reported data [19] where it was found that adsorbing the biosurfactant obtained from L. lactis 53 onto the surface of silicone rubber turned the surface more hydrophilic.

Further functional characterization was evaluated for the crude biosurfactant and isolated fractions. Crude biosurfactant and fraction A are efficient in comparison with synthetic surfactants, as sodium dodecylsulphate for example, with a cmc of $2.9 \mathrm{~g} / \mathrm{l}$ and surface tension $37 \mathrm{~mJ} / \mathrm{m}^{2}$ [27,28]. Although the isolated fraction A was not as effective (cmc of $14 \mathrm{~g} / \mathrm{l}$ and surface tension of $36 \mathrm{~mJ} / \mathrm{m}^{2}$ ) as many of biosurfactants described in the literature, for example sophorolipids obtained from Torulopsis bombicola with a cmc of $0.082 \mathrm{~g} / \mathrm{l}$ and surface tension $37 \mathrm{~mJ} / \mathrm{m}^{2}$ [28], it should be noted that the biosurfactant studied here was not as much purified as the ones described in the literature.

Fourier transform infrared absorption spectra and X-ray photoelectron spectroscopy data obtained for crude biosurfactant showed that it consist of a mixture of several compounds. From the results of absorption band ratios obtained for fraction A it can be concluded that there is no probability of this fraction being a pure protein, polysaccharide or fatty acid [3]. Table 3 includes $\mathrm{X}$-ray photoelectron spectroscopy data for reference compounds protein, salivary glycoprotein and lipoteichoic acid, and by comparison with the data for fraction $\mathrm{A}$, it can be concluded that this fraction is consistent neither with the data for lipoteichoic acid nor with the data for glycosidic residue, cholesterol or phospholipid for which the N/C ratio would be around 0 . The relatively high N/C ratio observed cannot solely be attributed to the presence of protein but is probably due to other nitrogen-containing compounds with $>\mathrm{NH}_{2}{ }^{+},>\left(\mathrm{NH}^{+}\right)-$or $=\left(\mathrm{NH}^{+}\right)-$groups, which can explain the absorption band at $2500 \mathrm{~cm}^{-1}$ in the infrared spectra. Therefore, the high N/C and O/C ratios together with the higher percentage of carbon involved in $\mathrm{C} 1$ bonds and oxygen $\mathrm{O} 1$ bonds indicate that this fraction probably contains glycoproteins. Proteinaceous biosurfactants, released by Lactobacillus species and named surlactin were also described by Velraeds et al. [3]. Further structural analysis should be developed in order to clarify the exact chemical structure of fraction A.

It is well known that the voice prostheses major weakness relies on the fact that the hydrophobic silicone rubber surface becomes rapidly colonized with a thick biofilm and in this perspective the anti-fouling improvement of the silicone rubber material is desirable. Conditioning silicone rubber voice prostheses with biosurfactants to achieve specific antimicrobial 
and anti-adhesive properties seems to be a pursuing strategy to increase their lifetimes, as described by Rodrigues et al. in previous work $[7,18,19]$. Furthermore, although the biosurfactants are not fully inhibiting the adhesion of yeast (Table 4) they are killed (Table 5), and therefore can be still used as an anti-fouling. The antimicrobial activity of biosurfactants against various microbes has been described before for surfactin [5] and viscosin [29], for example. However, the applicability of biosurfactants as coating agents is dependent on their stability at different pHs as saliva can exhibit $\mathrm{pH}$ variations according to the patient diet. Nevertheless, fraction A was found to be stable over a $\mathrm{pH}$ range from 5 to 9. Although only one purification step was included in this study, fraction A was found to be an anti-adhesive and antimicrobial agent against microbial strains isolated from explanted voice prostheses. Thus, a compromise situation must be achieved as further purification steps although yielding purer compounds, most of the times are not considered, especially since the downstream operations cost usually represents $50-80 \%$ of the total processing cost.

\section{Conclusions}

In conclusion, L. lactis 53 was found to release a glycoprotein-like biosurfactant that may interfere with microbial adhesion and cell growth onto silicone rubber voice prostheses. Further purification steps should be carefully analyzed as each purification step will increase the costs and decrease the amounts of biosurfactant recovered.

\section{Acknowledgments}

L.R. Rodrigues thanks FCT (Portugal) for the post doctoral grant SFRH/BPD/26064/2005. The authors acknowledge CACTI (Spain) for running the FTIR experiments and Joop de Vries (University of Groningen, The Netherlands) for running the XPS analysis.

\section{References}

[1] K. Jenny, O. Kappeli, A. Fietcher, Appl. Microbiol. Biotechnol. 36 (1991) 5 .

[2] M. Morikawa, H. Daido, T. Takao, S. Murata, Y. Shimonishi, T. Imanaka, J. Bacteriol. 175 (1993) 6459.
[3] M. Velraeds, H.C. van der Mei, G. Reid, H.J. Busscher, Colloid Surf. B: Biointerf. 8 (1996) 51.

[4] B. Angelova, H.-P. Schmauder, J. Biotechnol. 67 (1999) 13.

[5] F. Ahimou, P. Jacques, M. Deleu, Enzyme Microbiol. Technol. 27 (2000) 749.

[6] R. Maier, G. Soberon-Chavez, Appl. Microbiol. Biotechnol. 54 (2000) 625 .

[7] L.R. Rodrigues, H.C. van der Mei, J.A. Teixeira, R. Oliveira, Appl. Environ. Microbiol. 70 (2004) 4408.

[8] D. Vollenbroich, G. Pauli, M. Ozel, J. Vater, Appl. Environ. Microbiol. 63 (1997) 44

[9] D. Vollenbroich, M. Ozel, J. Vater, R.M. Kamp, G. Pauli, Biologicals 25 (1997) 289.

[10] M. Velraeds, B. van de Belt-Gritter, H.C. van der Mei, G. Reid, H.J. Busscher, J. Med. Microbiol. 47 (1998) 1081.

[11] G. Reid, Int. Dairy J. 10 (2000) 415.

[12] C. Heinemann, V. van Hylckama, D. Janssen, H.J. Busscher, H.C. van der Mei, G. Reid, FEMS Microbiol. Lett. 190 (2000) 177.

[13] H.C. van der Mei, B. van de Belt-Gritter, R. van Weissenbruch, F. Dijk, F.W.J. Albers, H.J. Busscher, Trans IChem. 77 (1999) 156.

[14] H.C. van der Mei, R.H. Free, G.J. Elving, R. van Weissenbruch, F.W.J. Albers, H.J. Busscher, J. Med. Microbiol. 49 (2000) 713.

[15] A. Bernheimer, L. Avigad, J. Gen. Microbiol. 61 (1970) 361.

[16] L. Thimon, F. Peypoux, J. Wallach, G. Michel, FEMS Microbiol. Lett. 128 (1995) 101.

[17] D. Kitamoto, H. Yanagishita, T. Shinbo, T. Nakane, C. Kamisawa, T. Nakahara, J. Biotechnol. 29 (1993) 91.

[18] L.R. Rodrigues, H.C. van der Mei, J.A. Teixeira, R. Oliveira, Appl. Microbiol. Biotechnol. 66 (2004) 306.

[19] L.R. Rodrigues, H.C. van der Mei, I.M. Banat, J.A. Teixeira, R. Oliveira, FEMS Immun. Med. Microbiol. 46 (2006) 107.

[20] M. Dubois, K. Gilles, J. Hamilton, P. Rebers, F. Smith, Anal. Chem. 28 (1956) 350

[21] L.R. Rodrigues, A. Moldes, J.A. Teixeira, R. Oliveira, Biochem. Eng. J. 28 (2006) 109.

[22] C.J. Boonaert, P.G. Rouxhet, Appl. Environ. Microbiol. 66 (2000) 2548, please check order.

[23] S. Stepanovic, D. Vukovic, I. Dakic, B. Savic, M. Scabic-Vlahovic, J. Microbiol. Meth. 40 (2000) 175.

[24] G. Elving, H.C. van der Mei, H.J. Busscher, A. Amerongen, E. Veerman, Laryngoscope 110 (2000) 321.

[25] W. Fischer, J. Microbiol. Meth. 25 (1996) 129.

[26] M. Morikawa, Y. Hirata, T. Imanaka, Biochim. Biophys. Acta 1488 (2000) 211

[27] C. Mulligan, G. Gibbs, Biosurfactants: Production, Properties and Applications, Marcel Dekker, New York, 1993.

[28] H.J. Busscher, C.G. van Hoogmoed, G. Geertsema-Doornbusch, M. van der Kuijl-Booij, H.C. van der Mei, Appl. Environ. Microbiol. 63 (1997) 3810.

[29] P. Singh, S. Cameotra, Trends Biotechnol. 22 (2004) 142. 